\title{
An update of the Culicoides (Diptera: Ceratopogonidae) checklist for the Balkans
}

\author{
Dubravka Pudar ${ }^{1}$, Dušan Petrić ${ }^{1}$, Xavier Allène ${ }^{2,3}$, Bulent Alten $^{4}$, Nazlı Ayhan ${ }^{5}$, Aleksandar Cvetkovikj, \\ Claire Garros ${ }^{2,3,7}$, Teufik Goletić ${ }^{8}$, Filiz Gunay ${ }^{4}$, Kristyna Hlavackova ${ }^{9}$, Aleksandra Ignjatović Ćupina', Mihaela Kavran? \\ Tereza Lestinova ${ }^{9}$, Bruno Mathieu ${ }^{10}$, Ognyan Mikov ${ }^{11}$, Igor Pajović ${ }^{12}$, Ignace Rakotoarivony ${ }^{2,3}$, Jovana Stefanovska ${ }^{6}$, \\ Slavica Vaselek', Almedina Zuko ${ }^{13}$ and Thomas Balenghien ${ }^{2,3,14^{*}}$
}

\begin{abstract}
Background: The prime significance of species belonging to the genus Culicoides Latreille, 1809 (Diptera: Ceratopogonidae) is their ability to transmit viruses such as bluetongue virus (BTV) to wild and domestic ruminants. Prior to 1998, BTV was considered exotic in Europe, but according to recent history of its outbreaks, it has become endemic in southern and eastern European countries circulating beyond its expected historical limits, into the Balkan region. The wind-borne long-distance dispersal of Culicoides spp. over water bodies and local spreading between farms emphasize the necessity of filling in the information gaps regarding vector species distribution. In most Balkan countries, data on Culicoides fauna and species distribution are lacking, or information is old and scarce.

Results: During this study, 8586 specimens belonging to 41 species were collected. We present the first faunistic data on Culicoides species in the former Yugoslav Republic of Macedonia (FYROM), Kosovo, Montenegro and Serbia. For other countries (Bosnia and Herzegovina, Bulgaria and Croatia), all historical records were compiled for the first time and then expanded with our findings to various extents. In all countries, confirmed or suspected BTV vector species belonging to the subgenera Avaritia and Culicoides were collected. The total number of species sampled during our field collections was 20 in Bosnia and Herzegovina (15 new records), 10 in Bulgaria (2 new records), 10 in Croatia (5 new records), 13 in FYROM, 9 in Kosovo, 15 in Montenegro, and 28 in Serbia. Of these, 14 species were registered for the first time in this part of the Balkans.

Conclusions: This paper provides the first data about Culicoides fauna in FYROM, Kosovo, Montenegro and Serbia, as well as new records and an update on the checklists for Bosnia and Herzegovina, Bulgaria and Croatia. These findings provide preliminary insights into the routes of BTV introduction and spreading within the Balkans, and present a valuable contribution to further research related to Culicoides-borne diseases in Europe.
\end{abstract}

Keywords: Culicoides, New records, Checklist, Balkans

\section{Background}

Biting midges of the genus Culicoides Latreille, 1809 (Diptera: Ceratopogonidae) are among the smallest hematophagous dipteran insects, usually $1-3 \mathrm{~mm}$ in body length, including at least 1368 extant species $[1,2]$.

Although Culicoides spp. cause a significant biting nuisance (impacting tourism and forestry) [3-5], their greatest importance lies in the fact that they are biological vectors

\footnotetext{
* Correspondence: thomas.balenghien@cirad.fr

${ }^{2}$ CIRAD, UMR ASTRE, F-34398 Montpellier, France

${ }^{3}$ ASTRE, University Montpellier, CIRAD, INRA, Montpellier, France

Full list of author information is available at the end of the article
}

of human and animal pathogens (mainly viruses, but also protozoans and filarial nematodes) [1, 5]. Indeed, the prime significance of Culicoides spp. is their ability to transmit viruses of domestic ruminants, such as bluetongue virus (BTV) or the novel Schmallenberg virus, which was first detected in 2011 in Germany [6].

Bluetongue (BT), which has to be reported to the Office International des Épizooties (OIE) [1, 7], is caused by BTV, affecting domestic and wild ruminants, in particular certain breeds of sheep (causing severe clinical disease and in some cases significant mortality) [8], but also cattle [9] and goats [10]. Bluetongue causes considerable economic

(C) The Author(s). 2018 Open Access This article is distributed under the terms of the Creative Commons Attribution 4.0 International License (http://creativecommons.org/licenses/by/4.0/), which permits unrestricted use, distribution, and 
concern and poses a major risk in the international trade of animals and animal products [11].

Prior to 1998, the disease was considered exotic in Europe [11], with just a few sporadic incursions recorded in southern European countries (Spain, Portugal, Greece and Cyprus) [12-14], but the situation has since dramatically changed. In the seven-year period from 1998 to 2005, BTV outbreaks were recorded in 15 southern European countries [11] and followed by sudden and unexpected outbreaks in northern Europe during 2006-2008 [14-17]. According to the European Food Safety Authority (EFSA) [8], this was arguably the largest and the most continuous outbreak of a Culicoides-borne pathogen in the history of humankind and caused enormous economic losses. Interestingly, BTV serotypes affecting southern and northern Europe are different [14]. Thanks to the implementation of compulsory BT vaccination in Europe resulting in a massive reduction of BTV cases, outbreaks were limited and some countries were back to a free BTV status.

When observing the situation in the Balkans, BTV-9 first entered southeastern Europe (Greece) in 1998 [18]. During 1999, this serotype spread from Greece to southeastern Bulgaria [19], while further outbreaks caused by BTV-9 were reported during 2001 in the former Yugoslav Republic of Macedonia (FYROM) [20], Kosovo [21], Montenegro, Serbia [22, 23] and Croatia [24, 25]. During the following year (2002), the BTV-9 outbreak was confirmed in Bosnia and Herzegovina [26] and Albania [27]. Interestingly, in the following years other serotypes of the virus were isolated in the Balkans: BTV-16 in Croatia during 2004, and an important BTV-4 epizootic in Greece, Bulgaria, Croatia, Serbia, Montenegro and FYROM in the period 2014-2017 [18].

According to the recent BT outbreak records in Europe, it is reasonable to state that BT is endemic in the countries of southern and eastern Europe and that different serotypes of BTV are still circulating through Europe.

Bluetongue emergence in previously unaffected regions of the Mediterranean basin has been attributed to climate change, through an increasing abundance of Culicoides imicola Kieffer, 1913, a proven Afrotropical vector species $[28,29]$. However, this was not applicable to the Balkan region as $C$. imicola did not occur (except in Greece) where BT outbreaks were recorded [11, 30-32]. Meanwhile, the Palaearctic species belonging to the subgenera Avaritia and Culicoides were found implicated as BTV vector species in different European countries [11, 33].

Laboratory and field studies reported the following species as probable BTV vectors: (i) subgenus Avaritia: Culicoides obsoletus (Meigen, 1818); Culicoides scoticus Downes \& Kettle, 1952; Culicoides dewulfi Goetghebuer, 1936; and Culicoides chiopterus (Meigen, 1830); (ii) subgenus Culicoides: Culicoides pulicaris (Linnaeus, 1758); Culicoides punctatus (Meigen,
1804); and Culicoides newsteadi Austen, 1921 [33-37]. In addition, Goffredo et al. [37] reported positive pools of the "Nubeculosus complex" [including Culicoides nubeculosus (Meigen, 1830), Culicoides puncticollis (Becker, 1903) and Culicoides riethi Kieffer, 1914] during the 2012-2014 BT epidemics in Italy, and recommended further studies to understand the possible vector role of these species.

Although the distribution or presence of Culicoides spp. are well studied in western Europe [38-41], published data on Culicoides fauna and species distribution for most Balkan countries are limited and there are no recent studies. To our knowledge, there are no published data for FYROM and Montenegro. In the late 1970s, Callot \& Kremer [42] carried out a few collections in former Yugoslavia, recording ten Culicoides spp. in Bosnia and Herzegovina and five Culicoides spp. in Croatia. Recently, new records were published in Bosnia and Herzegovina and in Kosovo. Reporting Culicoides obsoletus using morphological identification (wing pattern only) raises the question about the presence of this species or its sympatric related species (C. scoticus) [43], and describing identification at the species "complex" level [44], both bring up taxonomic concerns.

In Serbia, Pavlović et al. [45] reported four species $(C$. obsoletus, C. pulicaris, Culicoides parroti Kieffer, 1922 and $C$. nubeculosus) in a conference abstract, but the lack of details on the identification method does not allow an assessment as to whether these authors were referring to species or groups of species. Comprehensive checklists are available only for Croatia with 16 species [42, 46, 47], for Albania with 20 species [48] and for Bulgaria with 37 species $[49,50]$, for which Bobeva et al. [49] summed up previously published literature, mostly in Bulgarian language [51-53].

We assembled all Culicoides species records from the region, combining the data collected during field studies performed by several research groups and the historical records (for Bosnia and Herzegovina, Bulgaria and Croatia). In addition, we provide the first checklists for Culicoides species for FYROM, Kosovo, Montenegro and Serbia.

\section{Methods \\ Culicoides sampling}

Culicoides spp. collections in the study area (Fig. 1) were conducted during sand fly (Diptera: Psychodidae: Phlebotominae) and/or mosquito (Diptera: Culicidae) surveys. Therefore, the selection of sites and trap types was not specifically adjusted to Culicoides trapping, except once in Serbia when an Onderstepoort Veterinary Institute blacklight suction trap (OVI trap) was used [54]. All traps were run for one night and set up from approximately $1 \mathrm{~h}$ before sunset to $1 \mathrm{~h}$ after sunrise. 


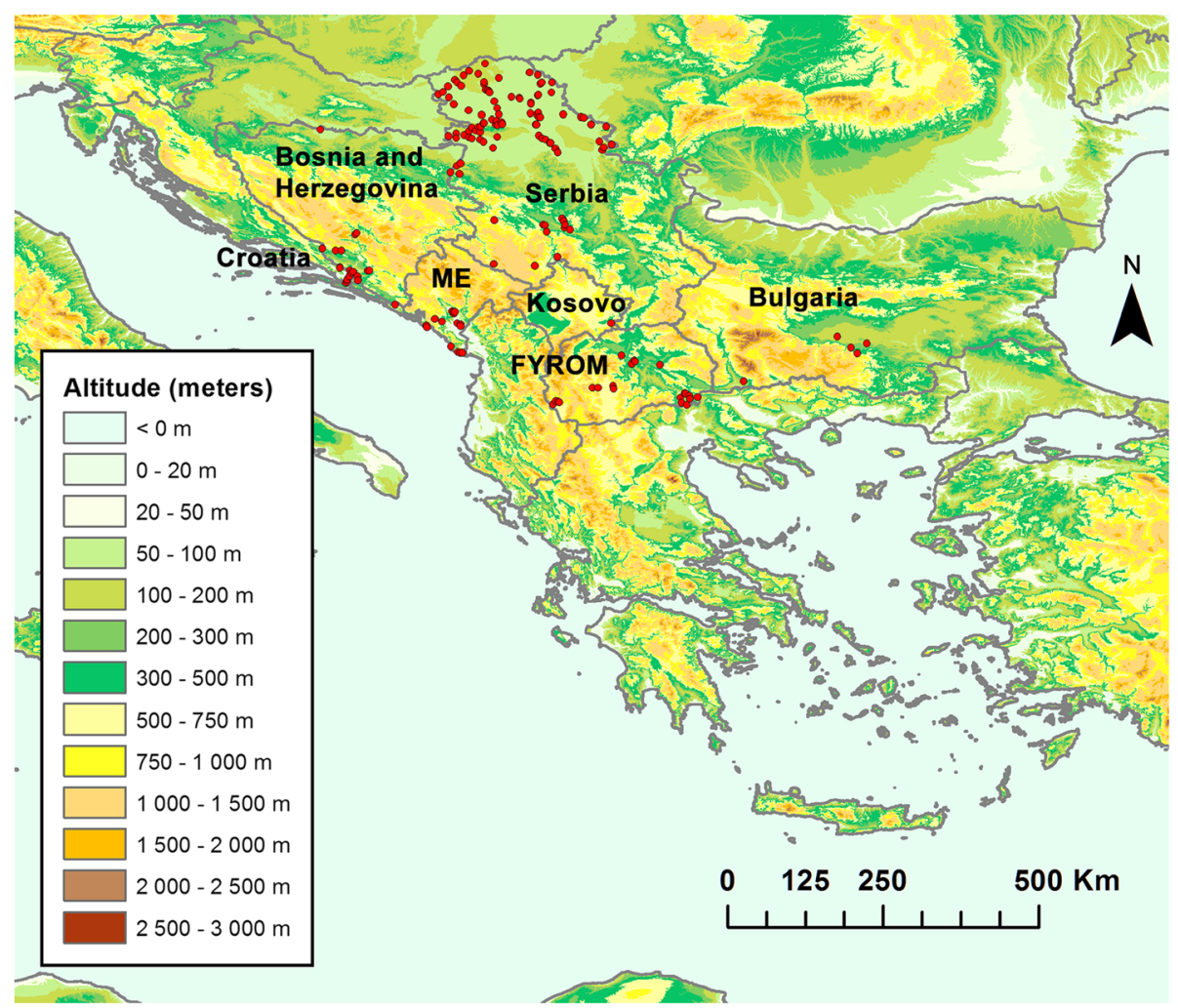

Fig. 1 Culicoides collection sites in the study area. A background elevation map was created with data produced by Jonathan de Ferranti and downloaded from viewfinderpanoramas.org. Abbreviations: ME, Montenegro; FYROM, the former Yugoslav Republic of Macedonia

In Bosnia and Herzegovina, 18 sites were surveyed over two periods. Five sites were sampled during a mosquito survey (17-22/06/2015) by NS2 dry ice-baited traps without light (constructed at the University of Novi Sad, Serbia), while another 13 sites were prospected during sand fly sampling (03-07/07/2015) using standard miniature Centre for Disease Control (CDC) light traps (John W. Hock, model 512, Gainesville, FL, USA) without dry ice.

In Bulgaria, 5 sites were sampled during sand fly collections (20-24/08/2015) using miniature CDC light traps with and without dry ice.

In Croatia, miniature CDC light traps without dry ice were used, during sand fly field studies (13-15/07/2015) at two sites.

In FYROM, 21 sites were sampled during a sand fly campaign (24/08/2015-14/09/2015) using miniature CDC light traps with and without dry ice.

In Kosovo, one site was surveyed (01-02/09/2015) using miniature $\mathrm{CDC}$ light traps without dry ice.

In Montenegro, specimens were obtained from 25 sites (urban, semi-urban and rural areas) during mosquito sampling (16-21/05/2015) by NS2 and BG-Sentinel traps (Biogents, Regensburg, Germany) baited with dry ice.
In Serbia, collections were undertaken at 124 sites (urban, semi-urban and rural areas) (28/04/2015-13/ 09/2015) during a West Nile virus surveillance program (81 sites, using NS2 traps only) and sand fly collections (43 sites). Within these 43 sites, 14 sites were exclusively sampled for sand fly collections and only CDC light traps without dry ice were used; at the other 29 sites, NS2 and miniature CDC light traps with and without dry ice were used and an OVI trap was placed only once. At these 29 sites, all mentioned trap types were sometimes positioned to potentiate the collection of Culicoides as well (depending on the number of animals and their composition, as well as farmers' permission for trap placing). According to the study context, the traps were placed bi-weekly, monthly or just once per collecting season in different parts of Serbia.

Culicoides biting midges in other surveyed countries were collected in traps positioned to sample sand flies (all traps in Bulgaria, Croatia, FYROM, Kosovo, and $72 \%$ of the traps placed in Bosnia and Herzegovina) and/or mosquitoes (all traps in Montenegro and 28\% of the traps in Bosnia and Herzegovina). In all countries, the sand fly surveys were carried out in farms (usually containing different mammal species and much rarely avian species). During the mosquito surveys, traps were positioned in 
different kinds of sites: highly urban (without any animal breeding); semi-urban (with different animal breeding); and rural (far away from human settlements and farms).

All sand fly-specific sites gained Culicoides spp. positive samples. Consequently, in the countries where only sand fly monitoring was performed, frequency of occurrence of different Culicoides spp. is expressed as a ratio of positive to all collection sites. As the sites for mosquito sampling were chosen according to different criteria, usually not comprising the courtyards, Culicoides spp. were not collected at all of them. Therefore, for Montenegro and Serbia, only the Culicoides spp. positive mosquito sampling sites were considered for the frequency of occurrence evaluation.

\section{Culicoides identification}

Species identification was carried out by observing morphological features under a stereomicroscope. Primarily, we focused on the wing pigmentation pattern and the distribution of wing macrotrichia. Then, we observed the antennal XI/X ratio (length of segment XI divided by length of segment $X)$, and the shape and size of the 3rd palpal segment. Finally, we compared all observed traits with IIKC (interactive identification key for Culicoides) database pictures [55]. Slide mounting was performed in the cases of morphologically similar species, atypical variations of the wing pattern, identification confirmation, or if the specimen was damaged. Slide-mounted specimens were observed under a light microscope connected to a camera and attention was paid to the broad range of other morphological features including shape, size and the number of female spermathecae, the shape and form of male genitalia [56, 57], as well as eye separation distance [55].

Culicoides obsoletus females cannot be morphologically separated with confidence from C. scoticus females or can be distinguished only by using many morphological measurements [58-60]. Thus, in our paper, we refer to C. obsoletus/C. scoticus females. However, males were recorded as $C$. obsoletus or C. scoticus, because they can be distinguished based on the appearance of the genitalia [55]. The Culicoides obsoletus taxon refers to C. obsoletus (sensu lato), i.e. potentially including the cryptic species, which have been recently discovered [61, 62].

In some cases, morphologically closely related species, or specimens with an atypical wing pattern (i.e. variations and overlapping between two species) could not be morphologically separated and identified with confidence. We refer to these as pairs of species, such as Culicoides fagineus Edwards, 1939/Culicoides subfagineus Delécolle \& Ortega, 1998; Culicoides lupicaris Downes \& Kettle, 1952/Culicoides pulicaris; Culicoides cataneii Clastrier, 1957/Culicoides gejgelensis Dzhafarov, 1964; and Culicoides jumineri Callot \& Kremer, 1969/
Culicoides kurensis Dzhafarov, 1960. Culicoides lupicaris was morphologically identified as described by Delécolle [63] since a formal redescription is missing [64]. We decided to associate sensu lato to Culicoides grisescens Edwards, 1939 to take into account the cryptic diversity highlighted recently within this taxon [61]. It is also worth noting that females of this species could be confused with Culicoides deltus Edwards, 1939. Although according to Borkent's catalog, Culicoides trivittatus Vimmer, 1932 belongs to the subgenus Oecacta [65], we decided to place it in "Miscellaneous unplaced species" (Table 1) since the male genitalia are very particular and very different from the type-species Oecacta furens [66]. However, in numerous trapping sites, the morphological identification to the species level of females and of males (confirmed by the observation of their species-specific genitalia appearance) was possible, providing us with information on the records of the members of the species complexes in most countries.

Furthermore, only a few specimens, too damaged to be assigned to a given species, were classified as Culicoides sp.

\section{Results}

A total of 8586 Culicoides specimens belonging to at least 41 species (at least 40 species classified in eight subgenera plus 1 miscellaneous unplaced species [55, 64-66]) were processed during our study (Table 1). Species of an additional two subgenera were recorded by previous authors (Table 1 ).

Only C. punctatus, C. newsteadi and C. obsoletus/C. scoticus were recorded in all inspected countries during our study. Three patterns of species presence/absence and frequency of occurrence were observed: the first in Bosnia and Herzegovina, Bulgaria, Croatia, FYROM and Kosovo; the second in Montenegro and the third, an intermediate pattern, in Serbia.

In Bosnia and Herzegovina, Bulgaria, Croatia, FYROM and Kosovo, the most frequent species were C. punctatus (recorded at $66 \%$ of sites), C. newsteadi (57\%) and $C$. obsoletus/C. scoticus (38\%), followed by C. pulicaris (30\%), Culicoides fascipennis (Staeger, 1839) (19\%) and C. fagineus/C. subfagineus (11\%). The less common species were Culicoides festivipennis Kieffer, 1914, C. lupicaris and C. cataneii/C. gejgelensis, while the remaining species were very rare. It should be emphasized that $C$. trivittatus was identified in Croatia; this represents the first record of the species in Europe.

The most frequent species recorded in Montenegro were Culicoides griseidorsum Kieffer, 1918 (recorded at $40 \%$ of sites) and C. festivipennis (24\%), followed by Culicoides alazanicus Dzhafarov, 1961, Culicoides pictipennis (Staeger, 1839) and C. newsteadi (16\% each). Culicoides punctatus and Culicoides minutissimus (Zetterstedt, 1855) were rare (12\% each). Records 
Table 1 Checklist of Culicoides records in Croatia, Bosnia and Herzegovina, Serbia, Montenegro, Kosovo, FYROM and Bulgaria

\begin{tabular}{|c|c|c|c|c|c|c|c|c|c|c|c|c|c|c|}
\hline \multirow[t]{2}{*}{ Culicoides species } & \multicolumn{2}{|c|}{ Croatia } & \multicolumn{2}{|c|}{$\begin{array}{l}\text { Bosnia and } \\
\text { Herzegovina }\end{array}$} & \multicolumn{2}{|c|}{ Serbia } & \multicolumn{2}{|c|}{ Montenegro } & \multicolumn{2}{|c|}{ Kosovo } & \multicolumn{2}{|c|}{ FYROM } & \multicolumn{2}{|c|}{ Bulgaria } \\
\hline & Pres & Ref & Pres & Ref & Pres & Ref & Pres & Ref & Pres & Ref & Pres & Ref & Pres & Ref \\
\hline Avaritia Fox & & & & & $\underline{x}$ & & $\underline{x}$ & & $\underline{x}$ & & $\underline{x}$ & & & \\
\hline Culicoides chiopterus (Meigen, 1830) & & & & & & & & & $\underline{x}$ & & & & & \\
\hline Culicoides dewulfi Goetghebuer, 1936 & & & & & & & & & & & & & $x$ & [49] \\
\hline Culicoides obsoletus/Culicoides scoticus & $\times$ & & $\times$ & {$[43]^{\mathrm{a}}$} & $\underline{x}$ & & $\underline{x}$ & & $\underline{x}$ & & $\underline{x}$ & & $\times$ & \\
\hline Culicoides obsoletus (Meigen, 1818) & * & {$[46,47]$} & & & $\underline{x}$ & & $\underline{x}$ & & & & & & * & [49] \\
\hline Culicoides scoticus Downes \& Kettle, 1952 & * & {$[46,47]$} & & & & & $\underline{x}$ & & & & & & * & [49] \\
\hline Beltranmyia Vargas & & & & & $\underline{x}$ & & $\underline{x}$ & & & & & & & \\
\hline Culicoides circumscriptus Kieffer, 1918 & * & {$[42,46,47]$} & $\times$ & {$[42]$} & $\underline{x}$ & & $\underline{x}$ & & & & & & * & [49] \\
\hline Culicoides manchuriensis Tokunaga, 1941 & & & & & $\underline{x}$ & & & & & & & & & \\
\hline Culicoides salinarius Kieffer, 1914 & & & $\underline{x}$ & & $\underline{x}$ & & & & & & & & * & [49] \\
\hline Culicoides Latreille & & & $\underline{x}$ & & $\underline{x}$ & & $\underline{x}$ & & $\underline{x}$ & & $\underline{x}$ & & & \\
\hline Culicoides deltus Edwards, 1939 & & & & & & & & & & & & & * & [49] \\
\hline Culicoides fagineus/Culicoides subfagineus & $\underline{x}$ & & $\underline{x}$ & & & & & & $\underline{x}$ & & & & $x$ & \\
\hline Culicoides fagineus Edwards, 1939 & * & {$[46]$} & & & $\underline{x}$ & & & & & & & & * & [49] \\
\hline Culicoides subfagineus Delécolle \& Ortega, 1998 & & & & & $\underline{x}$ & & & & & & & & & \\
\hline Culicoides flavipulicaris Dzhafarov, 1964 & & & & & $\underline{x}$ & & & & & & $\underline{x}$ & & $x$ & [49] \\
\hline Culicoides grisescens Edwards, 1939 (s.l.) & & & $\underline{x}$ & & & & & & & & $\underline{x}$ & & $x$ & [49] \\
\hline Culicoides impunctatus Goetghebuer, 1920 & & & & & & & & & & & & & * & [49] \\
\hline Culicoides lupicaris/Culicoides pulicaris & & & & & $\underline{x}$ & & & & & & & & & \\
\hline Culicoides lupicaris Downes \& Kettle, 1952 & & & $\underline{x}$ & & & & & & $\underline{x}$ & & & & $\underline{x}$ & \\
\hline Culicoides pulicaris (Linnaeus, 1758) & * & {$[46]$} & $\underline{x}$ & & $\underline{x}$ & & & & $\underline{x}$ & & $\underline{x}$ & & $\times$ & [49] \\
\hline Culicoides newsteadi Austen, 1921 & $\times$ & {$[47]$} & $\underline{x}$ & & $\underline{x}$ & & $\underline{x}$ & & $\underline{x}$ & & $\underline{x}$ & & $x$ & [49] \\
\hline Culicoides punctatus (Meigen, 1804) & $x$ & {$[46]$} & $\underline{x}$ & & $\underline{x}$ & & $\underline{x}$ & & $\underline{x}$ & & $\underline{x}$ & & $\times$ & [49] \\
\hline Monoculicoides Khalaf & & & & & $\underline{x}$ & & & & $\underline{x}$ & & $\underline{x}$ & & & \\
\hline Culicoides nubeculosus (Meigen, 1830) & & & & & $\underline{x}$ & & & & $\underline{x}$ & & & & * & [49] \\
\hline Culicoides parroti Kieffer, 1922 & & & & & & & & & & & & & * & [49] \\
\hline Culicoides puncticollis (Becker, 1903) & & & & & $\underline{x}$ & & & & & & & & $x$ & [49] \\
\hline Culicoides riethi Kieffer, 1914 & & & & & $\underline{x}$ & & & & & & $\underline{x}$ & & * & [49] \\
\hline Culicoides stigma (Meigen, 1818) & & & & & & & & & & & & & * & [49] \\
\hline Oecacta Poey & & & & & $\underline{x}$ & & $\underline{x}$ & & & & $\underline{x}$ & & & \\
\hline Culicoides brunnicans Edwards, 1939 & & & & & $\underline{x}$ & & & & & & & & & \\
\hline Culicoides dzhafarovi Remm, 1967 & & & * & {$[42]$} & & & & & & & & & & \\
\hline Culicoides longipennis Khalaf, 1957 & * & {$[42]$} & $x$ & {$[42]$} & $\underline{x}$ & & & & & & $\underline{x}$ & & * & [49] \\
\hline Culicoides picturatus Kremer \& Deduit, 1961 & & & $\underline{x}$ & & $\underline{x}$ & & $\underline{x}$ & & & & & & & \\
\hline Culicoides saevanicus Dzhafarov, 1960 & * & {$[46]$} & & & & & & & & & & & & \\
\hline Culicoides vexans (Staeger, 1839) & & & & & & & & & & & & & * & [49] \\
\hline \multicolumn{15}{|l|}{ Pontoculicoides Remm } \\
\hline Culicoides saevus Kieffer, 1922 & & & & & & & & & & & & & * & [49] \\
\hline Culicoides sejfadinei Dzhafarov, 1958 & & & * & {$[42]$} & & & & & & & & & * & [49] \\
\hline Culicoides tauricus Gutsevich, 1959 & & & & & & & & & & & & & * & [49] \\
\hline \multicolumn{15}{|l|}{ Remmia Glukhova } \\
\hline Culicoides schultzei (Enderlein, 1908) & & & & & & & & & & & & & * & [49] \\
\hline
\end{tabular}


Table 1 Checklist of Culicoides records in Croatia, Bosnia and Herzegovina, Serbia, Montenegro, Kosovo, FYROM and Bulgaria (Continued)

\begin{tabular}{|c|c|c|c|c|c|c|c|c|c|c|c|c|c|c|}
\hline \multirow[t]{2}{*}{ Culicoides species } & \multicolumn{2}{|c|}{ Croatia } & \multicolumn{2}{|c|}{$\begin{array}{l}\text { Bosnia and } \\
\text { Herzegovina }\end{array}$} & \multicolumn{2}{|c|}{ Serbia } & \multicolumn{2}{|c|}{ Montenegro } & \multicolumn{2}{|c|}{ Kosovo } & \multicolumn{2}{|c|}{ FYROM } & \multicolumn{2}{|c|}{ Bulgaria } \\
\hline & Pres & Ref & Pres & Ref & Pres & Ref & Pres & Ref & Pres & Ref & Pres & Ref & Pres & Ref \\
\hline Sensiculicoides Shevchenko & & & & & $\underline{x}$ & & $\underline{x}$ & & & & $\underline{x}$ & & & \\
\hline Culicoides alazanicus Dzhafarov, 1961 & & & * & {$[42]^{b}$} & $\underline{x}$ & & $\underline{x}$ & & & & & & * & [50] \\
\hline Culicoides begueti Clastrier, 1957 & & & $\underline{x}$ & & & & $\underline{x}$ & & & & & & & \\
\hline $\begin{array}{l}\text { Culicoides cataneii Clastrier, 1957/Culicoides gejgelensis } \\
\text { Dzhafarov, } 1964\end{array}$ & $x$ & {$[42]$} & $x$ & {$[42]$} & $\underline{x}$ & & $\underline{x}$ & & & & $\underline{x}$ & & * & [49] \\
\hline Culicoides clastrieri Callot, Kremer \& Deduit, 1962 & & & * & [42] & & & & & & & & & & \\
\hline Culicoides duddingstoni Kettle \& Lawson, 1955 & & & & & $\underline{x}$ & & & & & & & & & \\
\hline Culicoides festivipennis Kieffer, 1914 & $\underline{x}$ & & $x$ & {$[42]^{c}$} & $\underline{x}$ & & $\underline{x}$ & & & & $\underline{x}$ & & * & [49] \\
\hline Culicoides griseidorsum Kieffer, 1918 & $\underline{x}$ & & $\underline{x}$ & & $\underline{x}$ & & $\underline{x}$ & & & & & & & \\
\hline Culicoides haranti Rioux, Descous \& Pech, 1959 & * & {$[46]$} & & & & & & & & & & & & \\
\hline Culicoides indistinctus Khalaf, 1961 & & & & & & & & & & & & & $\underline{x}$ & \\
\hline $\begin{array}{l}\text { Culicoides jumineri Callot \& Kremer, 1969/Culicoides } \\
\text { kurensis Dzhafarov, } 1960\end{array}$ & $\underline{x}$ & & $\underline{x}$ & & & & & & & & & & * & [49] \\
\hline Culicoides kibunensis Tokunaga, 1937 & * & {$[42]^{d}$} & * & {$[42]^{d}$} & $\underline{x}$ & & $\underline{x}$ & & & & $\underline{x}$ & & & \\
\hline Culicoides maritimus Kieffer, 1924 & * & [47] & & & & & & & & & & & & \\
\hline Culicoides odiatus Austen, 1921 & & & & & $\underline{x}$ & & & & & & & & * & [49] \\
\hline Culicoides pictipennis (Staeger, 1839) & & & & & & & $\underline{x}$ & & & & & & * & [49] \\
\hline Culicoides shaklawensis Khalaf, 1957 & & & & & & & & & & & $\underline{x}$ & & * & [49] \\
\hline Culicoides simulator Edwards, 1939 & & & & & $\underline{x}$ & & & & & & & & * & [49] \\
\hline Culicoides submaritimus Dzhafarov, 1962 & & & $\underline{x}$ & & & & & & & & & & & \\
\hline Culicoides vidourlensis Callot, Kremer, Molet \& Bach, 1968 & * & {$[42]$} & * & [42] & & & & & & & & & & \\
\hline Silvaticulicoides Glukhova & & & $\underline{x}$ & & $\underline{x}$ & & $\underline{x}$ & & $\underline{x}$ & & $\underline{x}$ & & & \\
\hline Culicoides achrayi Kettle \& Lawson, 1955 & & & & & $\underline{x}$ & & $\underline{x}$ & & & & & & & \\
\hline Culicoides fascipennis (Staeger, 1839) & $\times$ & [46] & $\underline{x}$ & & & & & & $\underline{x}$ & & $\underline{x}$ & & * & [49] \\
\hline Culicoides ostroushkoae Glukhova, 1989 & & & & & & & & & & & & & * & [49] \\
\hline Culicoides pallidicornis Kieffer, 1919 & & & & & $\underline{x}$ & & & & & & & & * & [49] \\
\hline Culicoides subfasciipennis Kieffer, 1919 & & & $\underline{x}$ & & $\underline{x}$ & & & & & & & & * & [49] \\
\hline Wirthomyia Vargas & & & $\underline{x}$ & & $\underline{x}$ & & $\underline{x}$ & & & & & & & \\
\hline Culicoides minutissimus (Zetterstedt, 1855) & & & $\underline{x}$ & & $\underline{x}$ & & $\underline{x}$ & & & & & & & \\
\hline Culicoides reconditus Campbell \& Pelham-Clinton, 1960 & & & & & & & & & & & & & * & [49] \\
\hline
\end{tabular}

Miscellaneous unplaced species

Culicoides trivittatus Vimmer, 1932

Culicoides paolae Boorman, 1996

$\stackrel{\underline{\times}}{*} \quad[46]$

Abbreviations: Pres, presence; Ref, reference; FYROM, the former Yugoslav Republic of Macedonia

${ }^{a}$ Reported as Culicoides obsoletus but identified only by wing morphology

${ }^{\mathrm{b}}$ Reported as Culicoides musilator Kremer \& Callot, 1961

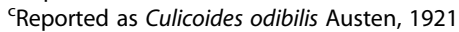

${ }^{\mathrm{d}}$ Reported as Culicoides cubitalis Edwards, 1939

Key: $\times$, the first record of certain species or subgenera in the country; $\times$, species recorded in previous studies and the present study; ${ }^{*}$ species recorded by previous authors

The subgenera and species are classified and presented in accordance with Borkent [65], Mathieu et al. [55], Ramilo et al. [64] and Szadziewski et al. [66]. C. indistinctus is presented in Borkent [65] as a synonym of $C$. odiatus. C. submaritimus is presented in Borkent [65] as a synonym of $C$. maritimus. Bobeva et al. [49] summed up previously published literature for Bulgaria, citing: Zilahi [51], Remm [52] and Nedelchev [53]

of other species (including C. obsoletus/C. scoticus) were negligible, whereas Culicoides pulicaris was not found.
The situation in Serbia seemed to be intermediate. Culicoides festivipennis was convincingly the most frequent species (recorded at 59\% of sites), followed by 
Culicoides circumscriptus Kieffer, 1918 and C. griseidosum (51\% and 49\%, respectively). Culicoides obsoletus/C. scoticus was recorded at $30 \%$ of sites, while C. punctatus and $C$. newsteadi were each found at $25 \%$ of the sites. Culicoides minutissimus, C. alazanicus, and C. pulicaris were less frequent, observed at $21 \%, 16 \%$ and $9 \%$ of sites, respectively. All other species were recorded at less than $8 \%$ of sites.

In the north of Serbia, more species were recorded during the sand fly surveys (27 spp.) than during the mosquito surveys (16 spp.), even if sampling was carried out in more sites and more frequently during mosquito surveys than sand fly surveys. Only one species, Culicoides kibunensis Tokunaga, 1937, was collected only during the mosquito surveys and not during the sand fly surveys. Finally, $C$. fagineus was recorded in the south-west of the country where only sand fly targeted sampling was performed. Additionally, in the north of Serbia where both mosquito and sand fly surveys were carried out, Culicoides were found in all sites sampled for sand flies, and only in $83 \%$ of the sites (67 out of 81 ) sampled for mosquitoes.

The total number of species recorded during this study was as follows: at least 20 in Bosnia and Herzegovina, at least 10 in both Bulgaria and Croatia, at least 13 in FYROM, at least 9 in Kosovo, at least 15 in Montenegro and at least 28 in Serbia (Table 1).

\section{Discussion}

This paper provides the first Culicoides faunistic data for FYROM, Kosovo, Montenegro and Serbia, and an update of the Culicoides species checklists by adding several newly recorded species: at least 15 for Bosnia and Herzegovina, two for Bulgaria, and at least five for Croatia (Table 1), as a preliminary and mandatory step prior to any further research related to Culicoides-borne diseases in this region of Europe.

Until recently, there was very limited information about Culicoides species in the territory of former Yugoslavia. In a short note format article, Callot \& Kremer [42] reported 12 Culicoides species based on adult emergence from mud samples collected in 1972, mainly along the coast of the Adriatic Sea (including present Bosnia and Herzegovina and Croatian territories). Additional studies in Bosnia and Herzegovina [43] and Croatia [46, 47] (Table 1) were carried out several decades later after this region was affected by a BTV outbreak [24-26], which acted as a trigger for Culicoides survey (re)starting. The same applies to Kosovo, where the "Obsoletus" and "Pulicaris" species complexes were reported, but without identification down to the species level [44], while for Serbia, due to the limited amount of published information (conference abstract) [45], it was not clear if the taxa mentioned were referring to species or to groups of species. Hence, we decided not to include these findings in the Serbian species checklist provided here. The research on Culicoides in Bulgaria has a much longer tradition and had been performed by several authors [49-53] (Table 1).

There were no previously published data on Culicoides in Montenegro. We recorded at least 15 species, but potential BTV vectors, such as C. obsoletus/C. scoticus or C. punctatus, which predominantly feed on large mammals [67] were very rare (only in a few localities), while $C$. newsteadi was present in more collection sites. The most frequently recorded species were C. griseidorsum, C. festivipennis, C. alazanicus, $C$. pictipennis and $C$. newsteadi. The species fauna was different compared to other countries surveyed in this study, which might be explained by the specific positioning of the traps aimed to sample mosquitoes. This sometimes may include rural locations (far away from human settlements and farms) or highly urban areas (without any cattle breeding). The two most common species found in Montenegro, namely C. griseidorsum and C. festivipennis, are known as predominant bird feeders [67], as well as $C$. alazanicus which was the third common species in our survey. Culicoides alazanicus shared the third position with $C$. pictipennis, which is an opportunistic feeder, and with $C$. newsteadi, which feeds exclusively on large mammals [50, 67]. Culicoides specimens were found in $28 \%$ of the traps positioned in urban sites, $64 \%$ in semi-urban sites and $8 \%$ in rural sites. Although semi-urban sites (with animal breeding) were more frequently sampled, the number of mammals was usually low ( $\leq 2$ in $69 \%$ of cases).

In the majority of countries, contrary to the study in Montenegro, the trap locations were selected mainly to meet requirements for sand fly sampling, i.e. all collection sites in Bulgaria, Croatia, FYROM and Kosovo, as well as $72 \%$ of the traps placed in Bosnia and Herzegovina. Finally, in Serbia, 11\% of the traps were set up exclusively for sand fly sampling, $24 \%$ of the collection sites were chosen for both sand fly and Culicoides sampling, while $65 \%$ of the traps were intended to mosquito survey. The traps set up for mosquitoes and collecting Culicoides were positioned in urban (15\%), semi-urban (66\%) and rural (19\%) sites.

Although Culicoides, sand flies and mosquitoes can be very often found in the same environment, the choice of the trap location (particularly presence of suitable hosts nearby) can influence the species composition of each group. Since all sand fly samplings were carried out on farms (usually containing different mammal species and, much more rarely, avian species), it is not surprising that Culicoides catches in surveyed countries other than Montenegro and Serbia were dominated by mammophilic species: $C$. punctatus, C. newsteadi, C. obsoletus/C. scoticus and C. pulicaris. 
In contrast, in Serbia, where 65\% of the traps were placed for mosquito sampling (including urban, semi-urban and rural areas), the species composition was dominated by predominately ornithophilic species, namely C. festivipennis, C. circumscriptus and C. griseidorsum, followed by predominately mammophilic feeders, namely $C$. obsoletus/C. scoticus, C. newsteadi and C. punctatus [67]. This kind of species composition and the occurrence frequency of Culicoides spp. indicates strong correlation with the host species present at each sampling site (the selection was tailor-made for the study purpose). Moreover, the sites sampled for sand flies may be more suitable for Culicoides inventory than those sampled for mosquitoes because we recorded more species in the first than in the second ones. Indeed, all sites sampled for sand flies were positive for Culicoides, whereas $17 \%$ of the sites sampled for mosquitoes were negative (when comparing catches in the north of Serbia). It should be noted, however, that these are preliminary estimations because the number of sampling sites and the sampling frequency were not the same for the different protocols.

Out of at least 41 species of Culicoides collected during our study, 14 species were recorded for the first time in this part of the Balkans (Table 1). Moreover, the finding of $C$. trivittatus in Croatia represents the first record of this species in Europe. This species is known to be distributed throughout Asia and middle Asia (Israel, Iran, Iraq, Armenia, Azerbaijan, Uzbekistan, Tajikistan, Turkmenistan and the south $50^{\circ} \mathrm{N}$ in Russia and Ukraine) [52].

\section{Conclusions}

We present the first data on Culicoides fauna in FYROM with at least 13 species, in Kosovo with at least 9 species, in Montenegro with at least 15 species and in Serbia with at least 28 species. For the other countries all previous Culicoides records (published independently by different author groups) were compiled for the first time and then expanded with our findings: at least 15 newly recorded species for Bosnia and Herzegovina, two for Bulgaria, and at least five for Croatia. Fourteen species were detected for the first time in the seven Balkan countries. Among the newly recorded species, $C$. trivittatus was recorded for the first time in Europe. Furthermore, due to sampling design, insights about species occurrence outside farm environments were provided. This can also serve as good starting point for research on ornithophilic Culicoides species, as well as surveillance of the bird pathogens they can transmit. In all countries, species of the subgenera Avaritia and Culicoides, which are proven or probable BTV vectors, were registered. This finding provides preliminary insights into the routes of BTV introduction and spreading within the Balkans.

\section{Abbreviations}

BT: bluetongue; BTV: bluetongue virus; CDC: Centre for Disease Control: FYROM: the former Yugoslav Republic of Macedonia; ME: Montenegro; OIE: Office International des Épizooties; OVI: Onderstepoort Veterinary Institute

\section{Acknowledgments}

The work of DPu, AIĆ, BA, SV and DPe was done under the frame of EurNegVec COST Action TD1303. We are very grateful to Dragan Dondur, Vit Dvorak, Ozge Erisoz Kasap, Ivelina Katerinova, Francis Schaffner, Vid Srdić, Oliver Stevanović, Ivona Subić and Simona Tchakarova for their help in the fieldwork.

\section{Funding}

The work was carried out under the VectorNet project (OC/EFSA/AHAW/ 2013/02-FWC1) funded by the European Food Safety Authority (EFSA) and the European Centre for Disease Prevention and Control (ECDC); projects TR31084 and III43007 were funded by the Ministry of Education, Science and Technological Development of the Republic of Serbia; WNV surveillance programs were funded by the Veterinary Directorate Ministry of Agriculture and Environment Protection of the Republic of Serbia and HERIC/LOVCEN project was funded by the Ministry of Science of Montenegro.

\section{Availability of data and materials}

All data generated or analyzed during this study are included in this published article and its additional files. Culicoides collections are stored in 70\% ethanol and are available for consultation at CIRAD (French Agricultural Research Centre for International Development), Montpellier, France (collections from FYROM, Montenegro, Serbia and part of Bosnia and Herzegovina) and at the University of Strasbourg, Medicine Faculty, Institute of Parasitology and Tropical Pathology, EA7292, Strasbourg, France (collections from Bulgaria, Croatia, Kosovo and other part of Bosnia and Herzegovina): http://ippts.unistra.fr/index.php/en/research/entomology/63en-collection-culicoides.

\section{Authors' contributions}

DPu contributed to manuscript writing and carried out Culicoides identification, data analysis, sample collection and processing. DPe contributed to manuscript writing, sample collection and processing. XA and IR carried out Culicoides identification. BA, NA, AC, TG, FG, KH, AIĆ, MK, TL, OM, JS, SV and AZ carried out sample collection and processing. IP carried out sample collection and processing, and data analysis. CG contributed to manuscript writing. BM contributed to manuscript writing and carried out Culicoides identification. TB contributed to manuscript writing and data analysis. All authors read and approved the final manuscript.

Ethics approval and consent to participate

Not applicable.

\section{Consent for publication}

Not applicable.

\section{Competing interests}

The authors declare that they have no competing interests.

\section{Publisher's Note}

Springer Nature remains neutral with regard to jurisdictional claims in published maps and institutional affiliations.

\section{Author details}

${ }^{1}$ Faculty of Agriculture, Department of Phytomedicine and Plant Protection, Laboratory for Medical and Veterinary Entomology, University of Novi Sad, Novi Sad, Serbia. ${ }^{2}$ CIRAD, UMR ASTRE, F-34398 Montpellier, France. ${ }^{3}$ ASTRE, University Montpellier, CIRAD, INRA, Montpellier, France. ${ }^{4}$ Faculty of Science, Department of Biology, Ecology Division, VERG Laboratories, Hacettepe University, Beytepe-Ankara, Turkey. ${ }^{5}$ Virology Unit, Faculty of Medicine, Aix-Marseille University, Marseille cedex 05, France. ${ }^{6}$ Faculty of Veterinary Medicine, Department of Parasitology and Parasitic Diseases, Ss. Cyril and Methodius University in Skopje, Skopje, Republic of Macedonia. ${ }^{7}$ CIRAD, UMR ASTRE, F-97490 Sainte Clotilde, Réunion. ${ }^{8}$ Veterinary Faculty, Department of Zootechnics and Poultry, University of Sarajevo, Sarajevo, Bosnia and Herzegovina. ${ }^{9}$ Faculty of Science, Department of Parasitology, Charles University in Prague, 2 Prague, Czech Republic. ${ }^{10}$ Medicine Faculty, Institute 
of Parasitology and Tropical Pathology, University of Strasbourg, EA7292 Strasbourg, France. ${ }^{11}$ National Centre of Infectious and Parasitic Diseases, Department of Parasitology and Tropical Medicine, Laboratory of Experimental and Applied Parasitology, Sofia, Bulgaria. ${ }^{12}$ Biotechnical Faculty, University of Montenegro, Podgorica, Montenegro. ${ }^{13}$ Veterinary Faculty, Department of Parasitology and Invasive Diseases, University of Sarajevo, Sarajevo, Bosnia and Herzegovina. ${ }^{14}$ IAV Hassan II, MIMC unit, Rabat, Morocco.

\section{Received: 17 January 2018 Accepted: 3 August 2018}

\section{Published online: 13 August 2018}

\section{References}

1. Mellor PS, Boorman J, Baylis M. Culicoides Biting midges: their role as arbovirus vectors. Annu Rev Entomol. 2000;45:307-40.

2. Borkent A. Numbers of extant and fossil species of Ceratopogonidae. 6, 2016. http://wwx.inhs.illinois.edu/files/4014/6785/5847/WorldCatalogtaxa.pdf. Accessed 22 Dec 2017

3. Hendry G, Godwin G. Biting midges in Scottish forestry: a costly irritant or a trivial nuisance? Scottish For. 1988;42:113-9.

4. Hendry G. Midges in Scotland. 5th ed. Glasgow: Bell and Bain; 2011.

5. Carpenter S, Groschup MH, Garros C, Felippe-Bauer ML, Purse BV. Culicoides biting midges, arboviruses and public health in Europe. Antiviral Res. 2013; 100:102-13.

6. Hoffmann B, Scheuch M, Höper D, Jungblut R, Holsteg M, Schirrmeier H, et al. Novel Orthobunyavirus in cattle, Europe, 2011. Emerg Infect Dis. 2012;18: 469-72.

7. OIE. OIE-listed diseases, infections and infestations in force in 2018. 2018. http://www.oie.int/en/animal-health-in-the-world/oie-listed-diseases-2018/. Accessed 7 Aug 2018.

8. EFSA. Scientific opinion of the scientific panel on animal health and welfare on request from the European Commission on bluetongue vectors and vaccines. EFSA J. 2007:479:1-29.

9. Callis J. Bluetongue in the United States. Prog Clin Biol Res. 1985;178:37-42.

10. Koumbati M, Mangana O, Nomikou K, Mellor PS, Papadopoulos O. Duration of bluetongue viraemia and serological responses in experimentally infected European breeds of sheep and goats. Vet Microbiol. 1999;64:277-85.

11. Saegerman C, Berkvens D, Mellor PS. Bluetongue epidemiology in the European Union. Emerg Infect Dis. 2008;14:539-44.

12. Mellor PS, Boorman J. The transmission and geographical spread of African horse sickness and bluetongue viruses. Ann Trop Med Parasitol. 1995:89:1-15.

13. Hendrickx G. The spread of blue tongue in Europe. Small Rumin Res. 2009; 86:34-9.

14. Sperlova A, Zendulkova D. Bluetongue: a review. Vet Med (Praha). 2011; 56:430-52.

15. Thiry E, Saegerman C, Guyot H, Kirten P, Losson B, Rollin F, et al. Bluetongue in northern Europe. Vet Rec. 2006;159:327.

16. Carpenter S, Wilson A, Mellor PS. Culicoides and the emergence of bluetongue virus in northern Europe. Trends Microbiol. 2009;17:172-8.

17. Wilson AJ, Mellor PS. Bluetongue in Europe: past, present and future. Philos Trans R Soc B Biol Sci. 2009;364:2669-81.

18. More S, Bicout D, Bøtner A, Butterworth A, Depner K, Edwards S, et al. Assessment of listing and categorisation of animal diseases within the framework of the Animal Health Law (Regulation (EU) No 2016/429): bluetongue. EFSA J. 2017;15:1-74.

19. Anonymous. Bluetongue in Bulgaria: follow-up report No. 1. Off Int des Epizoot Dis Inf. 2001;14:230-1.

20. Anonymous. Bluetongue in the former Yugoslav Republic of Macedonia: follow-up report No. 1. Off Int des Epizoot Dis Inf. 2001;14:265-8.

21. Osmani A, Murati B, Kabashi Q, Goga I, Berisha B, Wilsmore AJ, et al. Evidence for the presence of bluetongue virus in Kosovo between 2001 and 2004. Vet Rec. 2006;158:393-6.

22. Anonymous. Bluetongue in Yugoslavia. Off Int des Epizoot Dis Inf. 2001;14:280-1.

23. Djuricić B, Jermolenko G, Milosević B, Radojicić S, Debeljak Z, Tomić A. The first bluetongue virus isolation in Yugoslavia. Vet Ital. 2004;40:581-2.

24. Anonymous. Bluetongue in Croatia: suspected outbreak. Off Int des Epizoot Dis Inf. 2001;14:291-2.
25. Listeš E, Bosnić S, Benić M, Madić J, Cvetnić Ž, Lojkić M, et al. An outbreak of bluetongue virus serotype 9 in southern Croatia. Acta Vet Brno. 2011;80:331-6.

26. Velić $L$, Dukić B, Eterović T, Čamo D, Bajrović T. Seroprevalence of bluetongue virus in sheep in Bosnia and Herzegovina. Veterinaria. 2013; 62:193-201.

27. Di Ventura M, Tittarelli M, Semproni G, Bonfini B, Savini G, Conte A, et al. Serological surveillance of bluetongue virus in cattle, sheep and goats in Albania. Vet Ital. 2004;40:101-4

28. Guis H, Caminade C, Calvete C, Morse AP, Tran A, Baylis M. Modelling the effects of past and future climate on the risk of bluetongue emergence in Europe. J R Soc Interface. 2012;9:339-50.

29. Jacquet S, Garros C, Lombaert E, Walton C, Restrepo J, Allene X, et al. Colonization of the Mediterranean basin by the vector biting midge species Culicoides imicola: an old story. Mol Ecol. 2015;24:5707-25.

30. Mellor PS, Wittmann EJ. Bluetongue virus in the Mediterranean basin 19982001. Vet J. 2002:164:20-37.

31. Savini G, Goffredo M, Monaco F, de SP, Meiswinkle R. Transmission of bluetonque virus in Italy. Vet Rec. 2003:152:119.

32. Gerbier G, Parodi J, Biteau-Coroller F, Baldet T, Mathieu B, Zientara S, et al. Surveillance de la fièvre catarrhale ovine (bluetongue) en France et dans I'Ouest Méditerranéen: bilan et perspectives. Epidémiolie Santé Anim. 2006; 49:37-44.

33. Carpenter S, Lunt HHL, Arav D, Venter GJ, Mellor PS. Oral susceptibility to bluetongue virus of Culicoides (Diptera: Ceratopogonidae) from the United Kingdom. J Med Entomol. 2006;43:73-8.

34. Caracappa S, Torina A, Guercio A, Vitale F, Calabrò A, Purpari G, et al. Identification of a novel bluetongue virus vector species of Culicoides in Sicily. Vet Rec. 2003;153:71-4

35. De Liberato C, Scavia G, Lorenzetti R, Scaramozzino P, Amaddeo D, Cardeti $\mathrm{G}$, et al. Identification of Culicoides obsoletus (Diptera: Ceratopogonidae) as a vector of bluetongue virus in central Italy. Vet Rec. 2005:156:301-4.

36. Savini G, Goffredo M, Monaco F, Di Gennaro A, Cafiero MA, Baldi L, et al. Bluetongue virus isolations from midges belonging to the Obsoletus complex (Culicoides, Diptera: Ceratopogonidae) in Italy. Vet Rec. 2005; 157:133-9.

37. Goffredo M, Catalani M, Federici V, Portanti O, Marini V, Mancini G, et al. Vector species of Culicoides midges implicated in the 2012-2014 bluetongue epidemics in Italy. Vet Ital. 2015;51:131-8.

38. De Liberato C, Purse BV, Goffredo M, Scholl F, Scaramozzino P. Geographical and seasonal distribution of the bluetongue virus vector, Culicoides imicola, in central Italy. Med Vet Entomol. 2003;17:388-94.

39. Talavera S, Muñoz-Muñoz F, Pagès N. New insights on diversity, morphology and distribution of Culicoides Latreille, 1809 (Diptera: Ceratopogonidae) from northeast Spain. Ann la Soc Entomol Fr. 2011;47: 214-31.

40. Ander M, Meiswinkel R, Chirico J. Seasonal dynamics of biting midges (Diptera: Ceratopogonidae: Culicoides), the potential vectors of bluetongue virus, in Sweden. Vet Parasitol. 2012;184:59-67.

41. Sarvašová $A$, Kočišová A, Liptáková E, Hiavatá $H$, Mathieu B. First insights into indoor and outdoor Culicoides activity related to the risk period for bluetongue virus transmission in eastern Slovakia. Acta Parasitol. 2016:61:743-55.

42. Callot J, Kremer M. Note chronologique des Culicoides (Dipteres, Ceratopogonides) de Yugoslavie. Acta Parasitol lugosl. 1979;10:15-20.

43. Omeragić J, Vejzagić N, Zuko A, Jažić A. Culicoides obsoletus (Diptera: (eratopogonidae) in Bosnia and Herzegovina - first report. Parasitol Res. 2009;105:563-5.

44. Berisha B, Goga I, Hulaj B, Çaushi D, Sherifi K, Wilsmore AJ, et al. Entomological research on the vectors of bluetongue disease and the monitoring of activity of Culicoides in the Prishtinë region of Kosova. Vet Ital. 2010;46:431-7.

45. Pavlović I, Stanojević S, Rajković M, Šekler M, Plavšić B. Research of Culicoides (Insecta: Ceratopogonidae) in Serbia. Zrenjanin: Symp XVI Epizoot days Serbia; 2014. p. 87

46. Listes E, Bosnic S, Benic M, Lojkic M, Cac Z, Cvetnic Z, et al. Serological evidence of bluetongue and a preliminary entomological study in southern Croatia. Vet Ital. 2004:40:221-5.

47. Bosnic S, Beck R, Listes E, Lojkic I, Savini G, Roic B. Bluetongue virus in Oryx antelope (Oryx leucoryx) during the quarantine period in 2010 in Croatia. Vet Ital. 2015;51:139-43. 
48. Goffredo M, Delecolle JC, Semproni G, Lika A. Culicoides (Diptera: Ceratopogonidae) in Albania: results of the 2002 entomological survey for bluetongue. Vet Ital. 2004;40:209-11.

49. Bobeva A, Zehtindjiev P, Bensch S, Radrova J. A survey of biting midges of the genus Culicoides Latreille, 1809 (Diptera: Ceratopogonidae) in NE Bulgaria, with respect to transmission of avian haemosporidians. Acta Parasitol. 2013;58:585-91.

50. Bobeva A, Zehtindjiev P, llieva M, Dimitrov D, Mathis A, Bensch S. Host preferences of ornithophilic biting midges of the genus Culicoides in the eastern Balkans. Med Vet Entomol. 2015;29:290-6.

51. Zilahi G. Beitrage zur Fliegenfauna Bulgariens. I. Chironomiden. Bull la Société Entomol Bulg. 1934;8:152-8.

52. Remm H. Ceratopogonidae - Mycetophilidae. In: Soos A, editor. Catalogue of Palaearctic Diptera 3. Budapest: Akademiai Kiado; 1988.

53. Nedelchev N. Study of insects of the genus Culicoides (Diptera: Ceratopogonidae) in Bulgaria. Sofia: Central Research Diagnostic Veterinary Institute; 2008 (In Bulgarian).

54. Venter G, Meiswinkel R. The virtual absence of Culicoides imicola (Diptera: Ceratopogonidae) in a light trap survey of the colder, high-lying area of the eastern Orange Free State, South Africa, and implications for the transmission of arboviruses. Onderstepoort J Vet Res. 1994;61:327-40.

55. Mathieu B, Cêtre-Sossah C, Garros C, Chavernac D, Balenghien T, Carpenter $\mathrm{S}$, et al. Development and validation of IIKC: an interactive identification key for Culicoides (Diptera: Ceratopogonidae) females from the Western Palaearctic region. Parasit Vectors. 2012;5:137.

56. Cornet M. Caractères morphologiques utilisés pour l'identification des Culicoides (Diptera, Ceratopogonidae). Cah ORSTOM, sér Ent. méd Parasitol. 1974;12:221-9.

57. Wirth WW, Hubert AA. The Culicoides of Southeast Asia (Diptera: Ceratopogonidae). Gainesville: The American Entomological Institute; 1989

58. Garros C, Balenghien T, Carpenter S, Delécolle J-C, Meiswinkel R, Pédarrieu A, et al. Towards the PCR-based identification of Palaearctic Culicoides biting midges (Diptera: Ceratopogonidae): results from an international ring trial targeting four species of the subgenus Avaritia. Parasit Vectors. 2014;7:223.

59. Elbers ARW, Meiswinkel $R$, van Weezep $E$, van Oldruitenborgh-Oosterbaan MMS, Kooi EA. Schmallenberg virus in Culicoides spp. Biting midges, the Netherlands, 2011. Emerg Infect Dis. 2013:19:106-9.

60. Kluiters G, Pagès N, Carpenter S, Gardès L, Guis H, Baylis M, et al. Morphometric discrimination of two sympatric sibling species in the Palaearctic region, Culicoides obsoletus Meigen and C. scoticus Downes \& Kettle (Diptera: Ceratopogonidae), vectors of bluetongue and Schmallenberg viruses. Parasit Vectors. 2016;9:262.

61. Wenk CE, Kaufmann C, Schaffner F, Mathis A. Molecular characterization of Swiss Ceratopogonidae (Diptera) and evaluation of real-time PCR assays for the identification of Culicoides biting midges. Vet Parasitol. 2012;184:258-66.

62. Meiswinkel R, de Bree F, Bossers-De Vries R, Elbers ARW. An unrecognized species of the Culicoides obsoletus complex feeding on livestock in the Netherlands. Vet Parasitol. 2015;207:324-8.

63. Delécolle J-C. Nouvelle contribution à l'étude systématique et iconographique des espèces du genre Culicoides (Diptera: Ceratopogonidae) du Nord-Est de la France. Strasbourg: University Louis Pasteur Strasbourg; UFR des Sciences de la Vie et de la Terre; 1985.

64. Ramilo D, Garros C, Mathieu B, Benedet C, Allène X, Silva E, et al. Description of Culicoides paradoxalis sp. nov. from France and Portugal (Diptera: (eratopogonidae). Zootaxa. 2013;3745:243-56.

65. Borkent A. The subgeneric classification of species of Culicoides - thoughts and a warning. Last revised: May 16, 2016. http://wwx.inhs.illinois.edu/files/ 5014/6532/8290/CulicoidesSubgenera.pdf. Accessed 22 Dec 2017.

66. Szadziewski R, Filatov S, Dominiak P. A redescription of Culicoides griseidorsum Kieffer, 1918, with comments on subgeneric position of some European taxa (Diptera: Ceratopogonidae). Zootaxa. 2016:4107:413-22.

67. Martínez-de la Puente J, Figuerola J, Soriguer R. Fur or feather? Feeding preferences of species of Culicoides biting midges in Europe. Trends Parasitol. 2015;31:16-22.

\section{Ready to submit your research? Choose BMC and benefit from:}

- fast, convenient online submission

- thorough peer review by experienced researchers in your field

- rapid publication on acceptance

- support for research data, including large and complex data types

- gold Open Access which fosters wider collaboration and increased citations

- maximum visibility for your research: over $100 \mathrm{M}$ website views per year

At BMC, research is always in progress.

Learn more biomedcentral.com/submissions 